\title{
Arbor
}

\section{La experiencia emocional de la sexualidad: una perspectiva psicofisiológica*}

\section{Manuel Mas}

Arbor CLXII, 640 (Abril1999), 451-471 pp.

Este ensayo presenta unas reflexiones sobre la experiencia emocional y las bases psicofisiológicas del comportamiento sexual. Se discuten las dificultades conceptuales y metodológicas que ofrece el estudio cientifico de la sexualidad y el modo en que las afrontan sus investigadores. Se describen los principales correlatos neurobiológicos y endocrinos del comportamiento sexual obtenidos en animales de experimentación y en humanos, con énfasis en las peculiaridades que presenta el orden de los primates, especialmente los antropoides, con respecto a las demás especies en lo que respecta a su fisiología sexual. Se comentan los riesgos de basar reglas morales en observaciones conductuales erróneas.

Sexualidad es un término muy impreciso que, junto a sus derivados, se aplica a múltiples aspectos de la vida y sus problemas. Por ello es necesario comenzar por una definición de su significado. En el presente contexto nos referiremos a la sexualidad como el modo en que cada individuo se identifica como ser sexual, la orientación de sus preferencias sexuales y las formas en que se expresan. Específicamente, se tratará de la motivación, disponibilidad y capacidad para realizar experiencias sexuales y obtener gratificación de ellas.

La experiencia de la sexualidad representa uno de los aspectos más singulares y característicos de cada persona. Siendo influída por multitud de factores intrapsíquicos, interpersonales, culturales y au- 
tobiográficos, las enormes posibilidades de combinación de los mismos la convierten en una vivencia peculiar de cada sujeto. Estas influencias psíquicas y sociales operan sobre un substrato biológico, un organismo regido por un cerebro, cuyo estado funcional puede condicionar notablemente la respuesta del individuo. Sobre el sistema nervioso influyen también señales procedentes del propio organismo, destacando entre ellas las hormonales (Figura 1). Dicho componente biológico, compartido en lo esencial con los demás miembros de la especie, y en diversa medida con otros sectores del mundo animal, representa también uno de los aspectos de la sexualidad que ofrecen mayores posibilidades de escrutinio científico.

FIgURA 1. Influencias sobre la conducta sexual

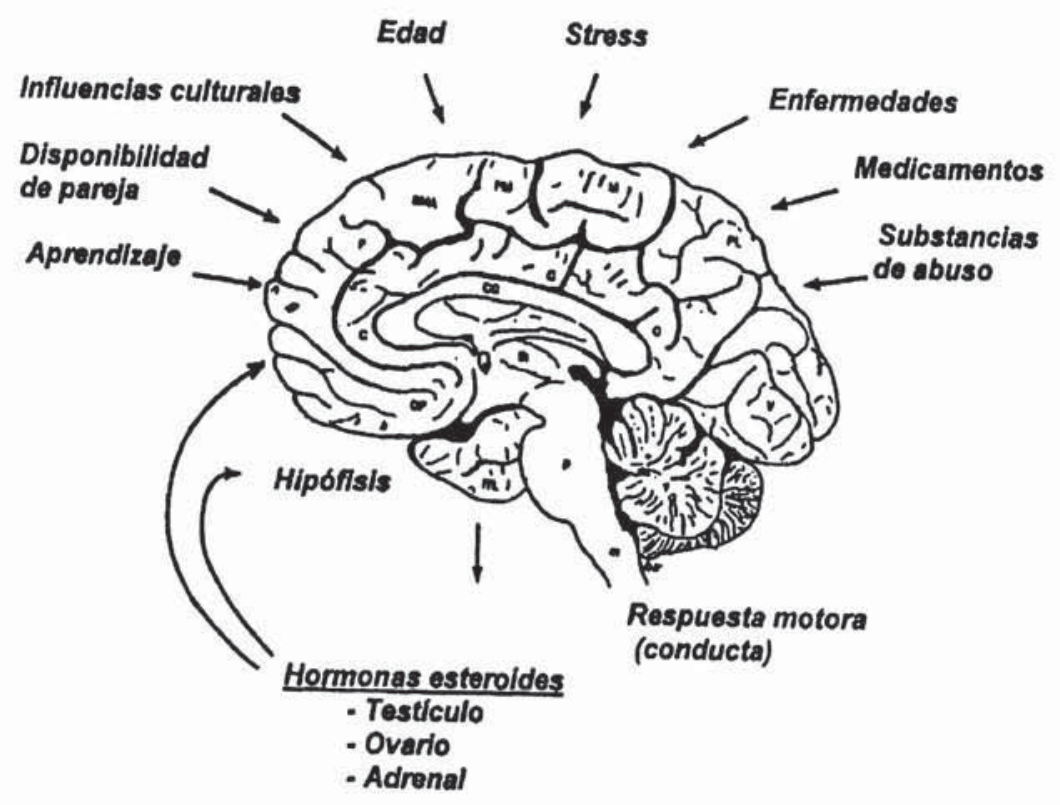

La sexualidad parece orientar buena parte del comportamiento de todos los animales. La intensidad de la motivación sexual puede competir con éxito, en cuanto a orientación de la conducta, con otras tan poderosas y esenciales para la supervivencia del organismo como las de ingesta de agua y alimentos o las de defensa y huida.

La sexualidad es ciertamente necesaria para la supervivencia de muchas especies, y parece representar un motor de su evolución, actuando como una importante fuerza selectiva. La reproducción sexual tiene la ventaja evolutiva de añadir variabilidad al carácter propagativo de la reproducción asexuada de las especies vegetales y animales más 
primitivas. Se acepta que tal variabilidad aporta mayores posibilidades adaptativas ante cambios ambientales. El éxito reproductor del individuo, y su influencia en el devenir de la especie, se basa fundamentalmente en la capacidad de esparcir los propios genes, así como en la de neutralizar a los competidores. Sin embargo es evidente, al menos en nuestra especie, que las funciones de la sexualidad trascienden a las estrictamente reproductivas.

En el ámbito de la psicología humana, se admite generalmente que la dimensión sexual está presente en gran parte de nuestra experiencia vital. La consecución de deseos y expectativas sexuales, o su fracaso, pueden llevar a los humanos a las mayores cotas de bienestar o de frustración, inspirar los más tiernos sentimientos o el mayor odio. La fascinación universal que la sexualidad ejerce sobre la mente humana ha quedado plasmada a lo largo de la Historia en múltiples manifestaciones literarias y artísticas de todo tipo, haciéndose patente en gran parte de las expresiones culturales de todas las sociedades y civilizaciones.

A la sexualidad han dedicado buena parte de su obra muchos de los pensadores más renombrados de las distintas culturas. Su papel fundamental en el desarrollo y expresión de la personalidad fue reconocido en influyentes elaboraciones teóricas de la Psicología de principios del siglo XX (Freud, Reich). Sin embargo, su conocimiento científico hubo de esperar más tiempo. Hace tan solo una veintena de años, Julian Davidson, pionero en este campo, señalaba que «la ambivalencia peculiar de nuestras actitudes hacia el sexo ha producido la paradoja de que mientras que esta área de la experiencia humana recibe una intensa e incesante atención en la literatura, las artes y la cultura popular, ha sido muy poco investigada por los científicos experimentales" [Davidson, 1982]. Desde entonces, afortunadamente, la sexualidad ha sido también objeto de una creciente investigación científica. Ello ha llevado a la formación de un cuerpo de conocimiento que, aunque todavía fragmentario, proporciona elementos de cierta solidez para la comprensión del fenómeno sexual. En el presente ensayo se revisan algunas de tales ideas. Se considerarán brevemente algunos aspectos comparativos relevantes del comportamiento animal y los datos existentes sobre humanos, a nuestro juicio más significativos, proporcionados por la investigación psicofisiológica, clínica y antropológica.

\section{Perspectiva comparativa: la sexualidad animal}

Las pautas de comportamiento sexual, siendo universales en su objetivo básico de conducir a la unión de los gametos (la fecundación), 
presentan una notable capacidad adaptativa. En general, en todas las especies estudiadas, parecen claramente orientadas a aumentar su eficacia reproductiva. En esta sección se comentan brevemente los aspectos más sobresalientes de la conducta sexual de los mamíferos que pueden contribuir a aclarar sus mecanismos.

\section{Efectos hormonales sobre la conducta sexual}

La conducta sexual representa el paradigma de la influencia que las hormonas pueden ejercer sobre el comportamiento y la actividad cerebral subyacente. En la mayoría de las especies la conducta de apareamiento, sobre todo en las hembras, sólo se manifiesta durante los limitados períodos fértiles de su ciclo reproductor. Dicha sincronización es proporcionada en gran parte por la acción de las hormonas ováricas sobre las estructuras cerebrales que controlan la expresión de la conducta sexual. Las principales hormonas femeninas, estrógenos, llamadas precisamente así por su propiedad de inducir la reacción de "estro" ${ }^{1}$ o "celo" en las hembras, alcanzan sus niveles plasmáticos máximos en el período preovulatorio, cuando la posibilidad de fecundación es mayor. Esto hace cambiar espectacularmente la conducta de la hembra que, de rechazar habitualmente cualquier aproximación sexual por parte de los machos, muestra ahora hacia ellos una conducta de solicitación (proceptividad) y posturas reflejas ${ }^{2}$ que facilitan los intentos de cópula del macho (receptividad). Este característico patrón de conducta estral desaparece al tiempo que la probabilidad de fecundación, para regresar al estado de "anestro", que suele ocupar la mayor parte del tiempo del ciclo reproductor. Una notable excepción a esta regla universal se encuentra en los primates, especialmente los antropoides. Por su especial relevancia para el comportamiento humano se comenta con mayor detalle más adelante.

En el macho la principal señal hormonal que influye sobre su comportamiento sexual es proporcionada por los andrógenos testiculares (esencialmente la testosterona). A estas hormonas se les atribuyen importantes efectos "organizativos" (diferenciación y desarrollo) y "activadores" (estimulación del comportamiento sexual en el adulto) sobre la función sexual. La menor ciclicidad de las secreciones gonadales del macho y la eficacia de sus andrógenos para mantener su función sexual, manifiesta en los relativamente pequeños niveles plasmáticos de estas hormonas que se requieren para la misma, determina el que ésta suela ser más estable que en la hembra. 
La experiencia emocional de la sexualidad...

La conducta sexual de casi todos los mamíferos es suprimida por la extirpación de las gonadas, tanto en el macho como en la hembra, aunque hay diferencias entre los sexos en cuanto al transcurso de este fenómeno. En las hembras suele desaparecer inmediatamente tras la castración, lo que se corresponde con la ya comentada rapidez con que se presenta y desvanece la fase estral del ciclo. Es restaurada, también tras un corto intervalo (de horas a pocos días), por el tratamiento con hormonas ováricas (esencialmente los estrógenos; en algunas especies coadyuvados por las progestinas). En los machos, los cambios en la expresión de la conducta asociados a la supresión de las hormonas androgénicas tardan más en manifestarse. Tras la castración hay una pérdida paulatina de las distintas pautas de la conducta sexual, cuya persistencia varia con las especies y los niveles previos de motivación y experiencia sexual del individuo. Así mismo, el tratamiento con andrógenos a los machos castrados requiere de períodos relativamente largos para la restauración de su conducta sexual. Estas diferencias reflejan las existentes entre ambos sexos en cuanto a organización de su "cerebro sexual".

Sin embargo el comentado patrón general de expresión de la motivación sexual, permanente en los machos y restringida en las hembras a cortos períodos periovulatorios de su ciclo ovárico, se desdibuja en gran medida en los primates. En buena parte de las especies de este orden, las hembras presentan unos intervalos más amplios de receptividad y proceptividad sexuales, extendiéndose éstas fuera de los limites del período fértil, aún cuando su actividad sexual sea máxima durante el mismo. Este fenómeno es especialmente pronunciado en los antropoides más próximos a nuestra especie como el chimpancé (Pan troglodytes) y, especialmente, el bonobo (Pan paniscus). Las hembras de esta especie copulan frecuentemente durante casi todos los días de su ciclo menstrual. En estos antropoides se encuentra también la mayor variabilidad de expresiones sexuales. Frente al patrón "clásico" de macho adulto montando a una hembra ovulante que responde con una estereotipada postura receptiva (lordosis o equivalente), estos animales presentan lo que se ha llamado "the scandalous behavior of the monkeyhouse». Aquí, además de cópulas heterosexuales entre adultos, se pueden observar en ambos sexos la estimulación de los genitales propios y de otros, las cópulas homosexuales, los juegos sexuales con crías jóvenes; en general prácticamente todas la combinaciones posibles, así como una cierta variedad de posturas coitales. Ello sugiere que en estas especies, tan próximas a la humana, la sexualidad ha adquirido un valor adaptativo distinto del reproductor. 


\section{Manuel Mas}

Cuáles sean las características de su configuración biológica que subyacen a este distinto significado de la expresión sexual no está completamente aclarado. Es probable que su mayor grado de desarrollo cerebral sea un factor importante. Hay también una importante conexión hormonal, proporcionada por la función androgénica de las glándulas suprarrenales. La corteza suprarrenal de los primates (incluídos los humanos) presenta la característica peculiar, extremadamente infrecuente en las demás especies, de secretar importantes cantidades de andrógenos, además de los mineralocorticoides y glucocorticoides comunes a casi todos los mamíferos. Dicha función androgénica adrenal es similar en ambos sexos. En el macho adulto es probablemente redundante ya que el testículo representa una fuente mucho más importante de estas hormonas (una excepción puede ser el período prepuberal, donde la activación de los andrógenos adrenales o «adrenarquía" precede a la maduración y desarrollo gonadales). En la hembra, sin embargo los andrógenos adrenales parecen contribuir de modo importante al mantenimiento de unos niveles relativamente estables de motivación sexual durante todo el ciclo ovárico, o buena parte del mismo. Experimentos con monas ovariectomizadas muestran la persistencia de la proceptividad hasta que se suprimen también la secreción androgénica adrenal, lo que coincide con observaciones clínicas en humanos.

En los primates, parece además que las áreas cerebrales sensibles a los andrógenos son similares en la hembra y el macho. Así, estudios de administración intracerebral de hormonas en el mono rhesus, muestran que las inyecciones de andrógenos en el hipotálamo anterior/area preóptica medial devuelve la proceptividad sexual a las hembras castradas y con las adrenales suprimidas (necesario para que se manifieste completamente el déficit androgénico, por las razones antedichas), de modo análogo a como restauran la motivación sexual a los machos castrados de todas las especies estudiadas (véase Johnson y Everitt, 1995, para un compendio de estos datos experimentales).

\section{Mecanismos neurales de la conducta sexual}

La identificación de los mecanismos cerebrales (núcleos y conexiones neurales, neurotransmisores, lugares y modos de acción de éstos) implicados en la regulación de una conducta tan compleja como la sexual presenta considerables dificultades, sólo resueltas parcialmente hasta el momento. 
Para el abordaje experimental de los neuromediadores que regulan las diversas conductas se ha recurrido tradicionalmente al empleo de fármacos que supuestamente actuarían a través de sistemas específicos de neurotransmisión. Numerosos estudios han documentado los efectos de diversos agentes neuroactivos sobre la función sexual. Entre los de mayor impacto sobre la conducta del macho, por ejemplo, destacan sobre todo los efectos generalmente estimulatorios de los compuestos que imitan o potencian la transmisión dopaminérgica, mientras que el bloqueo farmacológico de ésta inhibe dicha conducta. La manipulación farmacológica de la transmisión serotonérgica suele tener los efectos opuestos, aunque matizados por el tipo de receptor sobre el que se actúe. Así mismo, la estimulación de la transmision noradrenérgica (mediante bloqueantes $\alpha 2$ ) suele inducir actividad sexual, mientras que los agonistas opiáceos tienen intensos efectos inhibitorios [Pfaus y Everitt, 1995]. Sin embargo, la administración sistémica de fármacos, aún cuando tiene gran interés por su posible repercusión clínica, no permite discernir los mecanismos cerebrales en los que intervienen (incluídos sus lugares de acción). Para ello se recurre a la administración localizada de pequenas cantidades de dichos agentes en distintas zonas del cerebro, comparándose sus efectos. Recientemente, los neurotransmisores implicados en la función sexual se han comenzado a estudiar de un modo más fisiológico, mediante el análisis de los cambios que ocurren en sus niveles endógenos cuando se están produciendo los diversos fenómenos de dicha conducta. Ello se ha logrado con la utilización de técnicas de medida en vivo, como son la voltametría y la microdiálisis cerebral [Mas et al 1995].

Combinando los efectos de lesiones quirúrgicas y de inyecciones localizadas de fármacos con acciones supuestamente conocidas con los de mediciones de los cambios en los neurotransmisores endógenos que se asocian a diversos aspectos de la conducta sexual, se puede obtener una idea más precisa de los mecanismos neuroquímicos que la regulan a nivel cerebral. Se ofrece un resúmen de los aspectos mejor documentados. Hay que señalar que esta información dista de ser exhaustiva, puesto que son muchas las áreas cerebrales y los neuromediadores a los que se ha encontrado relación con los fenómenos sexuales.

Uno de los efectos sobre la conducta copulatoria masculina observado de modo más constante es el de su supresión tras la lesión del área preóptica medial y la adyacente región anterior del hipotálamo. Las lesiones bilaterales amplias de esta zona invariablemente llevan al cese de la actividad de cópula del macho en las diversas especies en que se ha estudiado [para referencias véase Mas, 1995]. Ello no se 
debe a un hipogonadismo secundario, puesto que la función testicular se suele mantener en niveles normales. También persisten los reflejos eréctiles y de emisión seminal cuando se examinan en contextos no sexuales. Se ha encontrado una estrecha asociación entre la actividad eléctrica y metabólica de neuronas situadas en el área preóptica y la expresión de la conducta sexual masculina en monos y ratas. Por otra parte, la región preóptica tiene una elevada densidad de receptores a las hormonas esteroides producidas por las gonadas y es el lugar donde la inyección de cantidades minúsculas de testosterona es capaz de restaurar con mayor eficacia la actividad copulatoria de los machos castrados.

En la hembra, las lesiones del area preóptica no suprimen el clásico reflejo de lordosis de los roedores (más bien suelen facilitarlo). Sin embargo, en las monas, las lesiones preópticas inhiben la conducta de solicitación (proceptividad). Además, como se mencionó arriba, en la hembra rhesus deprivada totalmente de andrógenos (es decir castrada y con las secreciones suprarrenales anuladas), su muy reducida conducta proceptiva es restaurada por la implantación de pequeñas cantidades de testósterona en el area preóptica e hipotalámica anterior, aunque no así la receptividad. Estos datos sobre monas apoyan la idea, apuntada arriba, de que la regulación de la conducta sexual del primate hembra (incluída con toda probabilidad nuestra especie) se asemeja más a la de los machos, al menos en sus aspectos apetitivos.

El area preóptica tiene una rica inervación que le aporta varios de los neurotransmisores a los que se atribuyen efectos más destacados sobre la función sexual. Así, recibe fibras opiatérgicas, fundamentalmente de, $\beta$-endorfina, procedentes del núcieo arqueado. La inyección de este péptido en el área preóptica tiene efectos inhibitorios sobre el comportamiento sexual. También se encuentran en esta región fibras aferentes monoaminérgicas procedentes del tronco cerebral cuya lesión tiene importantes efectos sexuales. Mediante diversos procedimientos neuroquímicos se ha encontrado que el inicio de la cópula se asocia con un aumento de la actividad dopaminérgica en el area preóptica, mientras que su culminación eyaculatoria se acompaña de una notable activación serotonérgica que, probablemente, contribuya a producir el fenómeno de saciación sexual [Mas et al 1995]. Ello explicaria en buena parte los efectos encontrados a las inyecciones locales en esta estructura de sustancias estimulantes de los receptores dopaminérgicos y serotonérgicos que inducen e inhiben, respectivamente, la conducta sexual masculina. Otros neuromediadores a los que se ha encontrado efectos marcados sobre la conducta sexual a su manipulación farmacológica 
localizada en el area preóptica son el $G A B A$, la aceticolina y el óxido nitrico.

El concepto tradicional del area preóptica como estructura esencial para la génesis de la motivación sexual ha sido matizado en tiempos recientes. El análisis más detallado, en diversas especies, del comportamiento masculino tras la lesión de aquella mostró que, si bien la actividad copulatoria efectiva desaparece, persisten otros signos de interés sexual. Así, tras recibir estas lesiones, los monos se masturban y, al igual que las ratas, realizan respuestas instrumentales para ganar acceso a las hembras receptivas, mostrando también preferencia por estar en la proximidad de éstas; las cabras siguen realizando conductas de cortejo, etc, aunque luego, en contacto con las hembras, ninguno de ellos llegue a realizar pautas de intromisión del pene y eyaculación. Tales datos indican que las lesiones del área preóptica lo que suprimen es la capacidad de realizar la cópula, más que la motivación sexual. Se sugiere así para esta estructura una función de traducción del estado de apetito sexual, originado en otro lugar, en las pautas motoras copulatorias específicas.

El empleo de técnicas de condicionamiento instrumental ha proporcionado una valiosa información sobre los mecanismos neurales de la motivación sexual. Así, se ha estudiado la denominada preferencia condicionada de lugar, que mide la tendencia del animal a regresar repetidamente al sitio donde ha copulado con anterioridad, y el refuerzo condicionado de segundo orden, basado en el aprendizaje de presionar un número determinado de veces una palanca para poder acceder a una hembra receptiva. Mientras que estas respuestas, como se ha mencionado arriba, no se afectan de modo importante por las lesiones preópticas, sí se ven influidas considerablemente por lesiones de otras zonas del SNC como el llamado sistema límbico y, en especial, de uno de sus componentes, la amígdala. Estudios en la rata macho han mostrado que los animales a los que se les ha destruido la porción basolateral de esta estructura en ambos lados, aunque copulan normalmente cuando se les pone en contacto con hembras receptivas, no realizan las referidas respuestas instrumentales para ganar acceso a ellas, es decir se trata del efecto opuesto al de las lesiones del área preóptica [Everitt 1990]. Se cree así que la amígdala, y probablemente otras estructuras límbicas, integren la información sensorial actual con el recuerdo de experiencias previas para la generación del apetito sexual. Mecanismos similares se han propuesto para otras conductas motivadas, como las de ingesta. Los neurotransmisores que se utilizarían en la amígdala o por las proyecciones que envía esta estructura para la realización de dichas funciones están poco documentados. 
Otra región cerebral que aparece muy implicada en estos fenómenos es la zona ventral del cuerpo estriado, especialmente el núcleo accumbens. Recibe aferencias límbicas, sobre todo de la amígdala y el hipocampo y se proyecta, con relevos en el pálido ventral y tálamo, a la corteza prefrontal y cingular. Está inervado también por fibras monoaminérgicas procedentes del tronco cerebral, entre las que destacan las dopaminérgicas originadas en el area tegmental vental. En la actualidad se atribuye al $\mathrm{n}$. accumbens un papel de "interfaz" entre los sistemas límbico y motor, esencial para la producción de respuestas conductuales adecuadas a los estados emocionales, adscribiéndosele a su inervación dopaminérgica una importante función moduladora de dichos procesos. Por ejemplo, se cree que representa un lugar de acción primordial de los fármacos antipsicóticos, la mayoría de los cuales son antagonistas dopaminérgicos y suelen tener efectos inhibitorios sobre la conducta sexual.

Por lo que respecta a la conducta sexual, y en consonancia con lo anterior, las lesiones con neurotoxinas de la inervación dopaminérgica del nucleo accumbens en ratas macho se ha encontrado que disminuye su actividad copulatoria con hembras hipoactivas (aunque no si muestran una elevada proceptividad). Por otra parte, las inyecciones de anfetamina (que produce liberación de monoaminas) en esta estructura aumentan las respuestas instrumentales para acceder a una hembra y diśminuyen las latencias de iniciación de la actividad copulatoria. Utilizando técnicas de registro neuroquímico en vivo, se ha comprobado que la actividad copulatoria del macho se acompaña de una liberación sostenida de dopamina en esta región, de magnitud muy superior a la observada durante otras interacciones sociales [Mas et al. 1995]. Estas observaciones se han extendido también a la hembra.

\section{Estudios psicofisiológicos y clínicos en humanos}

La investigación de la sexualidad humana, a diferencia de la conducta sexual animal, se suele enfocar en gran medida en el logro de un estado cognitivo, la percepción consciente de la satisfacción sexual [Davidson, 1982]. Este estado depende de la combinación de experiencias percibidas como originadas en el propio cuerpo o en el de la pareja. La excitación sexual puede ser provocada por diversos estímulos, tanto de origen externo (visuales, auditivos, olfatorios, tactiles) como intracerebral (fantasías, recuerdos, etc). Su procesamiento por el cerebro se traduce en el estado motivacional de deseo o apetito que dará lugar, a su vez, a la respuesta sexual. No es de extrañar, por tanto, que la 
función sexual se vea influida por hormonas que actúan sobre el cerebro así como por diversas lesiones de éste y por fármacos neurotrópicos.

Cuestiones conceptuales y metodológicas en el estudio de la sexualidad humana

Para el análisis fisiológico de la sexualidad es preciso distinguir entre sus componentes apetitivos, es decir los factores que inducen a un organismo a iniciar esta conducta o a aceptar la aproximación de otro y los consumatorios, entendiendo como tales el conjunto de pautas motoras, en gran parte reflejas, por las que se ejecuta dicha conducta. Al tratar del comportamiento sexual humano, a sus aspectos motivacionales y los consumatorios se les suele agrupar también, respectivamente, bajo los términos deseo (o, de modo más impreciso, líbido) y respuesta. Se sabe ahora que ambos procesos están regulados por mecanismos diferentes, y muchas de las disfunciones sexuales clínicas afectan de modo relativamente selectivo a una u otra de estas categorías. Como se verá, las influencias hormonales sobre los mismos son muy diferentes.

Deseo

El deseo sexual se puede conceptuar como la propensión a realizar actos sexuales, determinada conjuntamente por la sensibilidad a los estímulos eróticos y la motivación para responder a ellos. Es el resultado de complejas interacciones de procesos cognitivos, afectivos y neurofisiológicos [Bancroft, 1989]. El concepto de salud psíquica ideal requiere que el deseo sexual se experimente en el contexto del afecto que puede, o no, haberse iniciado con un comienzo apasionado. Como señala Levine [1992], tales circunstancias del inicio suelen ser, sin embargo, bastante irrelevantes para lo que suceda en el futuro, cuando la pareja deba afrontar los problemas derivados de la evolución personal de ambos componentes y el equilibrio de las necesidades individuales de cada uno de sus miembros. Dependiendo de cómo la pareja solucione esos desafíos, el deseo sexual puede persistir o desvanecerse.

Para la evaluación del deseo sexual se recurre a la información proporcionada por el individuo y, en ciertos aspectos, su pareja. Tales datos pueden ser de tipo subjetivo, como la frecuencia y el contenido de sus pensamientos y fantasías sexuales, el grado de satisfacción obtenido del sexo, etc., o bien cuantificando diversos tipos de actos 
sexuales realizados a iniciativa propia o de la pareja. Para la medición de todo ello se han ido desarrollando cuestionarios y escalas psicométricas que llegan a alcanzar una precisión considerable. No obstante, este tipo de investigación sigue presentando considerables dificultades metodológicas. Una muy importante es la cuestión de la generalización a la población de los hallazgos obtenidos. Al centrarse estos estudios en algunos de los aspectos más íntimos de la vida, de los que no todo el mundo está dispuesto a proporcionar información pormenorizada, son probables los sesgos en la ofrecida por los voluntarios que aceptan colaborar en ellas. Por otra parte, la experiencia disponible indica que hombres y mujeres recuerdan bastante mal los episodios sexuales del pasado, incluso reciente (tal como las dos semanas precedentes) [McCoy, 1998].

Tratándose de una conducta intensamente personal y privada, su estudio con técnicas científicas tradicionales, como la observación y medida resulta sumamente difícil. El proceso de obtención de datos sobre conductas sexuales requiere la exposición pública de conductas privadas o encubiertas. Ello invariablemente disminuye la precisión de lo que se recuerda (o manifiesta), especialmente cuando implica prácticas delicadas y relativas a tabúes culturales. Los auto-informes sobre conducta sexual están sujetos a una amplia gama de influencias, especialmente la de la deseabilidad social (es decir, contarle al investigador lo que se supone que éste quiere oir, o lo que es socialmente aceptable).

Por otra parte, las interacciones sociosexuales requieren de, al menos, una pareja. Puede haber cambios en los niveles de actividad o gratificación sexual que no dependan del propio sujeto, sino de su compañero/a, como su atractivo, su interés sexual, etc.

\section{Respuesta sexual}

Por lo que respecta a la respuesta sexual se pueden distinguir dos fases diferentes: excitación y orgasmo. Los aspectos más evidentes de las mismos son los cambios físiológicos que tienen lugar en los genitales, sin olvidar que hay también un importante componente extragenital que afecta a diversos órganos y sistemas. La fase de excitación se caracteriza por el aumento considerable de aporte sanguíneo a la pelvis y la región genital, debido a fenómenos localizados de vasodilatación. En el varón, se traduce en la erección del pene, y el aumento de secreciones glandulares del tracto genital, como la prostática. En la mujer da lugar a la erección del clítoris y pezones y la vasocongestión 
del suelo de la pelvis, con aumento de tamaño y dilatación de la vulva y lubricación vaginal.

La respuesta orgásmica consiste en contracciones tanto de musculatura lisa como de la esquelética. Manifestaciones del primer fenómeno son, en el hombre, la contracción del conducto deferente, enviando los espermatozoides en él almacenados hacia la uretra, y de las vesículas seminales y próstata, que vierten su contenido en la misma; en la mujer hay, a veces, contracciones uterinas. La contracción rítmica de los músculos estriados del suelo de la pelvis, hace estrecharse intermitentemente las paredes vaginales y el ano. En el varón, además, sirve para propulsar el líquido seminal a lo largo de la uretra, expulsándole con cierta fuerza.

Existe también un importante componente extragenital, con notables cambios cardiovasculares, respiratorios, del nivel de consciencia, etc., pues la actividad sexual implica una respuesta integrada de la totalidad del organismo. Entre ellos, cabe señalar los aumentos detectados en varios estudios, aunque hay también resultados negativos, en los niveles plasmáticos de diversas hormonas como gonadotrofinas, testosterona, cortisol, catecolaminas, prolactina y hormonas neurohipofisarias. El significado biológico de estos cambios hormonales es incierto, aunque hay sugestivas hipótesis sobre el tema (véase Mas, 1992, para una descripción más detallada de estos fenómenos). Como se ha apuntado arriba, la respuesta sexual, conlleva también importantes alteraciones del estado de consciencia; especialmente la experiencia orgásmica. Una discusión en profundidad de estos fenómenos y sus implicaciones puede encontrarse en Davidson [1982].

Las respuestas descritas arriba pueden ser cuantificadas en el laboratorio con la ayuda de instrumentación adecuada. Su medición ha contribuido de modo importante conocimiento actual de los mecanismos fisiológicos del funcionamiento sexual, incluídas sus bases neuroendocrinas. La observación directa por parte de los investigadores de los cambios fisiológicos que ocurren en los sujetos de estudio durante su actividad sexual (cópula o masturbación), tal como se realizaba en algunos de los estudios pioneros en el campo (como los de Masters y Johnson), hace tiempo que no se practica. En los laboratorios actuales de psicofisiología sexual, los sujetos experimentales permanecen aislados, con la máxima protección de su intimidad, mientras los registros de diverso tipo (electrofisiológicos, manométricos, etc.), así como tomas de sangre y otras muestras se realizan de modo automatizado. Se miden los cambios que muestran los citados indicadores en respuestas a diversos estímulos de tipo visual, auditivo, imaginario, etc., intentando 
relacionarlos con el estado del sujeto desde el punto de vista hormonal, de medicación, edad, posibles patologías, etc. Mientras que ello limita en cierta medida las posibilidades de estudio, su mayor aceptabilidad ética y social ha permitido una relativa proliferación de este tipo de laboratorios y la mayor participación de voluntarios como sujetos experimentales, lo que ha permitido un importante avance del conocimiento sobre los correlatos biológicos, especialmente los hormonales, de la sexualidad humana.

A pesar de dichos progresos, las dificultades para realizar una síntesis satisfactoria a partir de la información disponible actualmente son también considerables. Muchos de los estudios realizados presentan importantes problemas metodológicos, destacando entre ellos el del limitado tamaño de las muestras y sus probables sesgos, además de la escasez de datos relativos a la población general con los que poder comparar sus hallazgos, así como la heterogeneidad de los sujetos estudiados. Otro de los aspectos en los que existe una gran variabilidad entre los diferentes trabajos publicados es en la valoración de los posibles efectos inespecíficos de las hormonas u otros agentes farmacológicos sobre aspectos como sensación de bienestar, nivel de energía, estado de ánimo, etc. Su importancia deriva de la necesidad de controlar el llamado "efecto dominó" [Bancroft, 1989], por el cual la función sexual, $\mathrm{u}$ otras conductas específicas, pueden verse alteradas indirectamente por los cambios producidos en aquellos.

\section{Influencias hormonales}

Con la información disponible parece bien establecida la existencia de influencias hormonales, especialmente las gonadales, sobre la sexualidad humana. Los estrógenos son claramente necesarios para el mantenimiento del estado trófico del tracto genital femenino $y$ el buen funcionamiento de su respuesta a la estimulación sexual. Esto se hace especialmente patente en la vagina, y su déficit por castración quirúrgica o menopausia natural puede llevar con relativa frecuencia a dificultades en el coito. Su intervención directa en la génesis del deseo sexual parece más dudosa.

Las hormonas que parecen más claramente asociadas con los componentes apetitivo/motivacionales de la función sexual, en ambos sexos, son los andrógenos [Sherwin, 1988]. En lo que respecta al varón, esta noción sorprende poco, ya que es congruente con lo observado en los machos de multitud de especies animales. En la mujer, las posibilidades de analogía con otras especies y, por consiguiente, de utilización de 
modelos experimentales para su mejor conocimiento, son mucho más restringidas.

El fenómeno casi universal del estro está ausente en la hembra humana y otras antropoides. La motivación sexual de las primates superiores ya no sigue estrictamente las fluctuaciones del ciclo estral sino que puede manifestarse de modo continuo. Esto parece haberse logrado en la mona rhesus, y presumiblemente en otras especies aún más próximas a la humana, no por una completa emancipación de su conducta del estado endocrino, sino permitiendo que aquellas partes del cerebro que controlan el comportamiento sexual respondan en mayor medida a los andrógenos que a los estrógenos o las progestinas. A su vez, tal acción de los andrógenos, promotora de la motivación sexual femenina parece bastante privativa de los primates, careciendo virtualmente de parangón en otros animales. Dado que los andrógenos circulantes proceden tanto del ovario como de la adrenal y éstos son secretados de modo constante a lo largo del ciclo menstrual la hembra primate variaría durante el mismo en aspectos como su atractivo (dependiente de los estrógenos y su fluctuación cíclica), pero tendría contínuamente estimulada su proceptividad. Tan alto grado de emancipación del cerebro de la hembra de la influencia de las hormonas ováricas clásicas (estrógenos y progestinas) sobre la motivación sexual refleja probablemente un desarrollo evolutivo importante. La interpretación más plausible es la de que una fuente de hormonas estimulantes del interés sexual que sea independiente de las fluctuaciones propias del ciclo ovárico permite la expresión de esta conducta durante amplios períodos del mismo. Con ello y, a diferencia de la mayoría de los animales, que sólo copulan en estrecha asociación cronológica con la ovulación, la conducta sexual de las primates adquiere nuevos valores adaptativos, como es el de promover la cohesión grupal, muy necesaria en estas especies tan sociales, especialmente en lo que concierne al cuidado de las crías.

En la mujer, como se ha revisado arriba, las hormonas ováricas no son estrictamente indispensables para tener actividad coital. Ello se había interpretado tradicionalmente como prueba de la completa emancipación de la sexualidad en nuestra especie de las hormonas gonadales. Sin embargo, se ha señalado acertadamente que esta conclusión refleja el fallo en distinguir entre la capacidad para tener actividad sexual del deseo de realizarla [Wallen, 1990]. La información existente, de modo coherente con buena parte de lo conocido sobre otros primates, señala también a los andrógenos como las principales hormonas facilitadoras del apetito sexual femenino. En todo caso, es 
importante no confundir los conceptos de "apetito" con los de "receptividad". Aunque la mujer esté continuamente expuesta a unos niveles relativamente elevados de andrógenos adrenales y ováricos, como señalase Frank Beach "ninguna mujer está continuamente "receptiva". Cualquier varón que abrigue esta ilusión debe ser o bien muy viejo y con una corta memoria o alguien muy joven y destinado a una amarga decepción" [Beach, 1974].

El papel de los factores endocrinos en el componente apetitivo de la sexualidad se podría resumir señalando que no parece que las hormonas, en este caso los andrógenos, estimulen directamente la motivación sexual sino que influyan, junto con factores afectivos y cognitivos, en la excitabilidad del cerebro, aumentando la probabilidad de respuesta a estimulos sexualmente relevantes para el individuo, que pueden ser muy diferentes, dependiendo de la orientación, preferencias y experiencias sexuales previas de cada uno. En otras palabras, influirían en un hipotético umbral de estimulación erótica. Por ello, aunque los niveles de estas hormonas estén muy disminuidos, se puede lograr la inducción de una respuesta sexual mediante estímulos erógenos de mayor intensidad (como visuales, tactiles o afectivos). El otro componente que también parecen facilitar es la gratificación sexual percibida por el sujeto y de ahí su efecto reforzante sobre las conductas que llevan a ella.

\section{Correlatos cerebrales}

En humanos, por limitaciones éticas evidentes, no existe un cuerpo de información sobre mecanismos cerebrales del funcionamiento sexual mínimamente comparable al proporcionado por la experimentación sobre animales. La mayor parte de los datos disponibles los proporciona la observación clínica.

Destaca la elevada incidencia de disfunciones sexuales como secuela de lesiones cerebrales relativamente amplias de causa traumática, isquémica, tumoral o infecciosa, siendo las alteraciones del deseo las más frecuentes [Miller et al 1986]. Así mismo, en los enfermos de Parkinson de ambos sexos suele darse una disminución del deseo sexual, y en los varones dificultades de la erección, con frecuencia independientemente del grado de deterioro de la función motora. Por el contrario, el tratamiento con agentes dopaminérgicos que se da habitualmente a estos pacientes induce en ocasiones una aparente exacerhación del deseo sexual. 
La disminución del deseo es también frecuente tras lesiones relativamente circunscritas a la región hipotalámica (por tumores, o producidas quirúrgicamente), o en los raros casos de malformaciones congénitas del sistema olfatorio y del hipotálamo-septum, tales como los síndromes de Kallman y de Morsier. En estas circunstancias suelen coexistir diversos grados de hipogonadismo que hace difícil discriminar las causas neurológicas de las hormonales de dichos trastornos sexuales. En ocasiones, se observan también conductas sexuales anómalas tras las lesiones de los lóbulos temporales. En general, la información clínica disponible no permite precisar con detalle las áreas del cerebro humano específicamente implicadas en la generación del deseo o la respuesta sexuales. No obstante, es bastante congruente con los datos, mucho más abundantes, proporcionados por la investigación en animales.

Recientemente han comenzado a aparecer informes basados en estudios funcionales de neuroimagen sobre correlatos cerebrales de la respuesta sexual. Parecen apuntar hacia la existencia de una importante asimetria en cuanto actividad y flujo sanguíneo en diversas zonas de la corteza cerebral durante la excitación o el orgasmo. Se han encontrado aumentos importantes de estos parámetros en la corteza prefrontal [Tiihonen et al 1994] y la circunvolución cingular anterior [Redoute et al, 1997], ambas del hemisferio derecho. Estas observaciones, aunque preliminares muy prometedoras, recuerdan antiguas descripciones de fenómenos de asimetría en registros electroencefalográficos realizados durante el orgasmo (revisadas en Davidson, 1982).

Con respecto a los neurotransmisores que intervienen en los mecanismos de generación y expresión del apetito sexual humano se carece de datos de localización como los proporcionados por la experimentación animal. Se dispone, sin embargo, de una creciente información acerca de efectos, deletéreos o beneficiosos, sobre el interés o el rendimiento sexuales de muchos fármacos neurotrópicos, o con acciones sobre hormonas, administrados generalmente para tratar otros problemas, así como de diversas substancias de abuso [Rosen 1991, Demyttenaere et al 1998]. En general, sus efectos sobre el funcionamiento sexual del humano concuerdan bastante bien con los encontrados en los animales de experimentación, lo que permite suponer que actúen mediante mecanismos análogos.

\section{Perspectiva antropológica}

El estudio comparativo de las diversas culturas, tanto contemporáneas como de diversos períodos históricos precedentes muestra la 
extraordinaria variabilidad de la experiencia sexual humana [Beach y Ford 1974, Nevid et al. 1995]. Un denominador común a casi todas ellas es la tendencia a reglamentarla, a establecer e incentivar pautas aceptables, así como límites cuya transgresión conlleva severas condenas o rechazo social. Las diferencias interculturales se dan en cuanto a la amplitud de tales márgenes. Aunque hay prohibiciones comunes a la generalidad de las culturas, como el incesto, la variación en las prácticas sexuales y actitudes sociales ante el sexo es enorme. Así, se encuentran desde culturas francamente sexófobas (las menos), en las que la expresión de la sexualidad queda restringida a poco más de los requisitos indispensables para la reproducción, hasta otras en que permiten, o fomentan, sus más variadas manifestaciones. Por ejemplo, en algunas culturas, como los Sambia de Nueva Guinea, la ingesta del semen de adultos por parte de los adolescentes varones se considera un importante estimulante del desarrollo de la masculinidad. Igualmente, en la considerada cuna de la civilización occidental, la Grecia clásica, los adolescentes se iniciaban sexualmente con adultos del mismo sexo como parte de su proceso educativo.

En nuestra tradición cultural, la expresión de la sexualidad no ha gozado de gran aprobación de la ideología oficial. La postura de la Iglesia Católica ha sido, y así continúa, muy restrictiva al respecto. Vetada su práctica a su propio clero, se admite como mal menor, necesario para la reproducción, pa־a el resto de la población; siempre que se ajuste a los límites del matrimonio, por otra parte indisoluble. El carácter esencialmente procreativo de la actividad sexual permisible sigue siendo destacado en los documentos normativos contemporáneos. Valgan como ejemplo las encíclicas "Humanae Vitae» y "Veritatis Splendor" probablemente los más elaborados de los textos eclesiásticos relevantes, los diversos discursos y escritos del actual Papa y las manifestaciones habituales de la jerarquía eclesiástica en materia sexual.

Tal postura se basa en gran medida en la llamada "ley natural", ya invocada por Tomás de Aquino y otros influyentes filósofos de la tradición cristiana. Por «ley natural", idea que se remonta a los filósofos griegos precristianos, se entendería lo que la Naturaleza ha enseñado a todos los animales, no sólo a la especie humana. De ahí que pueda inferirse de la observación del comportamiento de otros animales. La constatación de que en la mayoría de ellos la cópula sólo se hace en períodos fértiles y está orientada a facilitar la fecundación ha llevado a considerar como "natural" sólo la actividad sexual directamente procreativa y como "antinaturales", y de ahí gravemente pecaminosas, 
La experiencia emocional de la sexualidad...

todas las que no lo parezcan. Como se ha criticado desde el propio campo católico [Heaney, 1994], dicha concepción tiene un importante fallo epistemológico, al estar basada en una "mala biología", en la observación de las especies erróneas. El mundo animal de cuyo comportamiento los padres medievales podían tener algún conocimiento era el de los animales domésticos. Como se mencionó antes, los mamíferos no primates muestran unas pautas de conducta sexual estrechamente acopladas a los generalmente breves períodos en que la fertilización es posible. Sin embargo, como también se explicó arriba, no es este el caso de nuestros parientes más próximos, chimpancés y bonobos, de cuya observación carecían los referidos autores. Sería importante que el pensamiento eclesiástico terminase de asimilar las implicaciones de la evolución de las especies, y el valor adaptativo de su comportamiento. Se comprendería así que los datos aportados por la "biología de granja» no son los más útiles para comparar, y entender, el comportamiento sexual humano.

Lo que la correcta Biología y Psicología Comparada, la Antropología, la Historia y la experiencia clínica nos enseñan es la enorme variabilidad de la expresión de la sexualidad en la especie humana y otras próximas produciéndose además, en la gran mayoría de las ocasiones, en momentos y circunstancias incompatibles con la fecundación. Esta perspectiva más amplia y realista de la sexualidad permite verle funciones más extensas que las meramente generativas. $\mathrm{Su}$ importante contribución al equilibrio emocional, la autoestima, la expresión y reparación afectiva, el intercambio de placer, el alivio de tensiones, la cohesión social y un largo etcétera, debe ser incorporada a cualquier consideración seria sobre la función de la sexualidad.

La sexualidad puede concebirse, con buen fundamento, como un patrimonio o recurso que puede ser bien gestionado hacia la satisfacción personal, la buena salud mental ${ }^{3}$ y el amor a otras personas y a uno mismo. Por el contrario su utilización inadecuada puede conducir hacia la frustración, la desesperanza, el embarazo no querido, la enfermedad y la muerte. No es desde la ignorancia o el rechazo apriorístico sino desde la compresión de sus implicaciones biopsicosociales, basada en la mejor ciencia posible, como ese recurso se puede gestionar con mayor eficacia. Aquí, el fisiólogo no pretende suplantar al moralista, pero sí cree que las personas sean capaces de asumir con mayor congruencia y solidez las conductas orientadas por sus creencias morales si se tiene un conocimiento crítico de sus fundamentos biológicos y psicológicos. 


\section{Notas}

\section{* Dedicado a JULIAN M. DAVIDSON}

1 Estro: del Griego oı $\tau \rho \circ \sigma=$ tábano. En la Antigüedad se atribuía el peculiar cambio de conducta de las hembras del ganado a la picadura o el zumbido de este insecto.

2 En los animales de laboratorio se suele objetivar cuantificando su "reflejo de lordosis", cuyo estudio ha proporcionado útiles informaciones sobre los mecanismos de acción de las hormonas ováricas sobre el Sistema Nervioso.

3 Véase Lehrman [1993] para una interesante discusión de las implicaciones terapéuticas del placer

\section{Bibliografía}

Abramson, P.R., Pinkerton, S.D.: With Pleasure. Thoughts on the Nature of Human Sexuality. Oxford Univ. Press, New York, 1995.

Bancroft, J.: Human sexuality and its problems, $2^{a}$ ed., Churchill Livingstone, Edinburgh, 1998.

BANCRoft, J.: Sexual behavior. En "Measuring Human Problems". D.F. Peck y C.M. Shapiro (eds), Wiley, New York, pp. 339-373, 1990.

BEACH, F. A.: Human sexuality and evolution. En Reproductive Behavior. W. Montagan y W. A. Sadler (eds), New York, Plenum Press, 333- 366, 1974.

BeAch, F. A., Ford, C.S.: Patterns of Sexual Behavior. Versión castellana: Conducta Sexual, $3^{\text {a }}$ ed., Fontanella, Barcelona, 1978.

Chaid-Durand, G., Hédon, B.: Sexualité et religions. Journal d'Obstetrice et Gynecologie 5, 1-13, 1997.

Davidson, J. M.: The Psychobiology of Sexual Experience. En J. M. Davidson y R. J. Davidson (eds.) The Psychobiolgy of Consciousness. Plenum Press. New York. pp. 271-332, 1982.

Demyttenaere K., De Fruyt J., Sienaert P.: Psychotropics and sexuality. International Clinical Psychopharmacology, 13 (suppl. 6), S35-S46, 1998.

EverITT, B. J.: Sexual motivation: a neural and behavioural analysis of the mechanisms underlying appetitive and copulatory responses of male rats. Neuroscience and Biobehavioral Reviews 14, 217-232, 1990.

Heaney, R.P.: Sex, natural law and bread crumbs. America, Feb 26, 12-16, 1994.

Johnson, M. H., EveriтT, B. J.: Essential Reproduction, $4^{\text {th }}$ edition. Blackwell Science, Oxford, pp. 130-142, 1995.

Kano, T.: The last ape: pygmy chimpanzee behavior and ecology. Stanford University Press, Stanford, 1992.

Lehrman, N.S.: Pleasure heals. Archives of Internal Medicine 153, 929-934, 1993.

Levine, S. B.: Sexual Life. A Clinician's Guide. Plenum Press, New York, 1992.

Mas, M.: Fisiología de la respuesta sexual. En Fisiología Humana, J. A. F. Tresguerres (ed.), McGraw Hill-Interamericana, Madrid, pp. 1181-1190, 1992.

MAs, M.: Neurobiological correlates of masculine sexual behavior. Neuroscience and Biobehavioral Reviews 19, 261-277, 1995. 


\section{La experiencia emocional de la sexualidad...}

Mas, M.: Neurotransmisores y comportamiento Sexual. En: "Hormonas, Instintos y Emociones». J. Botella y J. A. F. Tresguerres, (eds) Ed. Complutense, Madrid, pp. 179-197, 1996.

Mas, M.: Bases neuroendocrinas de la sexualidad humana. En "La Evolución de la Sexualidad y los Estados Intersexuales». J. Botella-Llusiá y A. Fernández de Molina (eds). Diaz de Santos. Madrid pp. 177-200, 1997.

Mas, M., Fumero, B., Gonzalez-Mora, J. L.: Voltammetric and microdialysis monitoring of brain monoamine neurotransmitter release during sociosexual interactions. Behavioural Brain Research 71, 69- 79, 1995.

Mccoy N L.: Methodological problems in the study of sexuality and the menopause. Maturitas, 29: 51-60, 1998.

Miller, B., Cummings, J.L., McIntyre,H., Ebers, G., Grodes, M.: Hypersexuality or altered sexual preference following brain injury. Journal of Neurology Neurosurgery and Psychiatry 49, 867-893, 1986

NADLER, R. D.: Proximate and ultimate influences on the regulation of mating in the great apes. American Journal of Primatology 37 93-102, 1995.

Nevid, J. S., Fichner-rathus, L., Rathus, S. A.: Human Sexuality in a World of Diversity, Allyn \& Bacon, Boston, 1995.

Pfaus, J. G., Everitr, B.J.: The psychopharmacology of sexual behavior. En: Psychopharmacology: The Fourth Generation of Progress. F. E. Bloom, D. J. Kupfer (eds), Raven Press, New York, pp. 743-758, 1995.

Redoute, J., Stoleru, S., Gregoire, M.C., Cinotti, L., Lavenne, F. Le Bars, D., Magnin, F., SPIra, A., Pujol, J.E.: Functional neuroanatomy of sexual arousal in healthy males. International Academy of Sex Research. Proceedings p. 50, 1997.

Rosen, R.C.: Alcohol and drug effects on sexual response: human experimental and clinical studies. Annual Review of Sex Research 2: 119-179, 1991.

SHERwin, B.B.: A comparative analysis of the role of androgen in human male and female sexual behavior: behavioral specificity, critical thresholds, and sensitivity. Psychobiology 16, 416-425, 1998.

Thionen, J., Kuikka, J., Kuplla, J., Partanen, K., Vainio, P., Airaksinen, J., Eronen, M., Hallikainen, T., Pannila, J., Kinnumen, I., Httunen, J.: Increase in blood flow of right prefrontal cortex in man during orgasm. Neuroscience Letters 170, 241-243, 1994.

WALLEN, K.: Desire and ability: hormones and the regulation of female sexual behavior. Neuroscience and Biobehavioral Reviews 14, 233-241, 1990. 